\title{
Evaluation of Human-Oriented Transport in City Hall Transportation Projects Approach to Sustainable Case Study of the Kerman City Hall
}

\author{
Sedigheh Meimandi Parizi*, Abdolreza Kazeminiya \\ Department of Civil Engineering, Sirjan University of Technology, Sirjan, Iran \\ Email: sm_parizi20@yahoo.com, kazeminiya14@yahoo.com
}

Received 21 July 2015; accepted 19 September 2015; published 22 September 2015

Copyright (C) 2015 by authors and Scientific Research Publishing Inc.

This work is licensed under the Creative Commons Attribution International License (CC BY). http://creativecommons.org/licenses/by/4.0/

(c) $\underset{\mathrm{EY}}{\mathrm{C}}$ Open Access

\section{Abstract}

In Iran, the implementation of public transport and non-motorized transport infrastructure warrants the need to allocate adequate funding from the state and city hall. In this regard, in city hall development plans (the format approved by the Ministry of Interior), urban transportation plan has been one of the ten chapters. The purpose of this paper is to survey the content and documents related to the allocation of funds to the traffic sector in the former development program of Kerman city hall and by the way, assess the role of human-oriented transportation among the plans and programs of Kerman city hall. Therefore, the amount of funds allocated to the transport sector in Kerman city hall development plans and programs has been investigated for a period of six years (2009-2014). Comparative analysis method is used for surveying the position and the importance of sustainable transport among planners and urban management. Kerman is the historical city and the most important city in the South East of Iran. Due to uncontrolled population growth in recent decades, a large number of cars added to its pathways, so it is required to have a plan of sustainable transportation programs to be evaluated traffic. Results of the analysis indicate that the budget allocated to the development of the vehicle-oriented transportation is much more than human-oriented transportation and in fact, human-oriented systems of transport such as walking and cycling are considered less than the others. Also in the old fabric of Kerman city that has formed on the basis of the human-oriented transportation, the lowest level of funding is intended to regulate transportation. With this description, it is clear that achieving sustainable development and human-oriented in urban transport sector, it fundamentally needs paradigm shift in urban transport development and revision in the attitudes of managers and planners, and in the meantime it is necessary to correct the programming cycle of urban development along with review of the allocating funds mechanism and to define projects in various sectors. Urban and

\footnotetext{
${ }^{*}$ Corresponding author.
}

How to cite this paper: Parizi, S.M. and Kazeminiya, A. (2015) Evaluation of Human-Oriented Transport in City Hall Transportation Projects Approach to Sustainable Case Study of the Kerman City Hall. Journal of Building Construction and Planning Research, 3, 149-161. http://dx.doi.org/10.4236/jbcpr.2015.33015 
transport planners can conduct municipalities projects with costing not too much and hereto provide non-motorized styles in the field of urban transport networks. If only allocated apart of the overall funding for roads, highways and city streets to the development of public transport and non-motorized transportation options, the impact would be very high.

\section{Keywords}

\section{Sustainable Transport, Human-Oriented Transportation, Non-Motorized Transport, The Funding of City Hall Programs}

\section{Introduction}

According to recent U.N. statistics, the majority of the world's inhabitants live in cities, many of which are developed without public and sustainable transportation infrastructure [1]. In these cities, they often use cars for trips within the city and other transportation options such as cycling, walking are rarely used [2]. Traffic disrupted presence in these cities in recent decades and lack of infrastructures for movement of this volume of vehicles, make inappropriate living conditions for residents and have created major traffic issues [3]. Vehicles and generally motorized transport equipment need extensive communication network, countless intersections, much flooring, roads, bridges, highways and parking that all of these involve major costs and on the other hand, they cause the extent and distribution of land uses and spaces [4]. Francis Tibaldz believes that the construction of roads in addition to being costly, damages to the environment. His solution for the traffic problem is to use public transport and pedestrian traffic [5]. While in part of the West world, people are trying to get release of the car and they try to dominate the desirable aspects of the city's pedestrian and transit revives [6], and proponents of walking and bicycling active modes of transportation commonly cite benefits to both personal health and the environment [7]. In many developing countries without significant development in the transit system, they jump from walking cities to car-oriented cities [8]. In developed countries, the subject of human-oriented transport (as one of the pillars of sustainable transport) instead of car-oriented has created a big change in their attitude about transport and especially in the environment. An attitude is that considers the people transportation instead of vehicle transportation. The result of such an approach was placing priority of public transportation, strengthening and expanding the network of sidewalks and bike lanes, considering the urban spaces to create the motivation for walking. Human-oriented transport is the main approach to urban environmental protection that in many developed countries, people try to distance themselves from vehicle-oriented transportation as much as possible and replace human-oriented transportation [3]. The city and transportation planners can provide field of non-motor patterns in traffic network and lead the transportation of the cities to the human-oriented transport, in the form of guidance city hall projects with low costs. Access to a city where walking and cycling are values, priorities and common is not an imaginary program, and it is easily possible so that human experience has shown, and it is necessary that attention should be paid to develop this system in the city plans [9]. In Iran, allocating adequate funding from both government and municipalities is essential for implementation of infrastructures of public and non-motorized transport.

In this article, urban traffic plans have been titled as one of the ten chapters in the five-year plans of city halls (format approved by the Ministry of Interior). This paper examines the content and documents related to the amount of funds allocated to the traffic in the Kerman city hall development program and comparative analysis method is used to check the status and importance of development of the human-oriented and sustainable transportation planning and urban management. For this purpose, by reviewing the literature and theoretical research, overview of the importance of the transport walking-based and human-orientated is obtained, then via survey of the budget allocated to traffic sector in former development plans of Kerman municipal in a six-year period (2009-2014). The status of sustainable transport and humanitarian is determined in plans and programs of Kerman municipal as one of the major cities in developing country of Iran.

\section{Literature Review}

Studies of urban transport have many changes over the past 50 years. The main emphasis of transportation stu- 
dies in the early decades was on the increasing capacity to meet the rising demand for travel by motor vehicles. Next studies, concerns the emphasis on pathways capacity development, showed widening of city streets, unlike popular belief not lead to a reduction in traffic volume and intensity [10]. The results of an experimental study at the University of California at Berkeley, shows that for every 10 percent annual increase in roads capacity, 9 percent will be added to traffic volumes in 4 years. About 60 to 90 percent of the new road capacity is become full in 5 years. Total traveling by vehicles increases 1 percent, for every 2 to 3 percent increasing in highways [11]. Newman and Kennethversi study on different cities around the world shows that more use of cars, will increase consumption of gasoline and pollution. The progress of urban transport systems in the world shows that the auto industry in recent decades has changed approach to the implementation and use of public transport [12].

Recently, several reports and other publications have estimated various benefits of walking and bicycling based on the share of vehicular travel that could be replaced by AT. The California Department of Public Health (CDPH) applied its integrated transport and Health Impacts Model (I-THIM) to illustrate impacts of long-term AT substitution scenarios. The most ambitious scenario modeled for the San Francisco Bay Area predicts a 45\% reduction in GHG emissions and 2236 fewer deaths and 22,807 years of life gained by 2035 [13]. Grabowetal (2012) estimated AT substitution scenarios in terms of environmental impacts (as particulate matter reductions) if all round-trips under eight kilometers by on-road light-duty vehicles were replaced by AT. Substitution potential scenarios yield estimated savings as high as $\$ 4247.5$ million [14].

Anthony Danz, an economist at the Brookings Institution, believes that traditional approaches to solve the traffic problem was trying to "enlarging pipes" and in other words was developing the streets. However, this approach only temporarily solves the issue. He believes that, to solve the problem of traffic we must decrease the volume of fluid or, "the number of vehicles" which is reduced by increasing the effects of traffic at peak hours or on busy streets [15]. Developing pathways and after that build bridges and non-coplanar intersections, alone will not solve the traffic problem, but It is possible that become helpful in aggravation and in some ways will result moving traffic from one point to another (Figure 1).

\section{The Study Area}

The study area is the capital of Kerman province, Kerman City. The city has four urban region and has a population about 650 thousand people [16]. According to surveys conducted in the city more than 50\% of the citizens
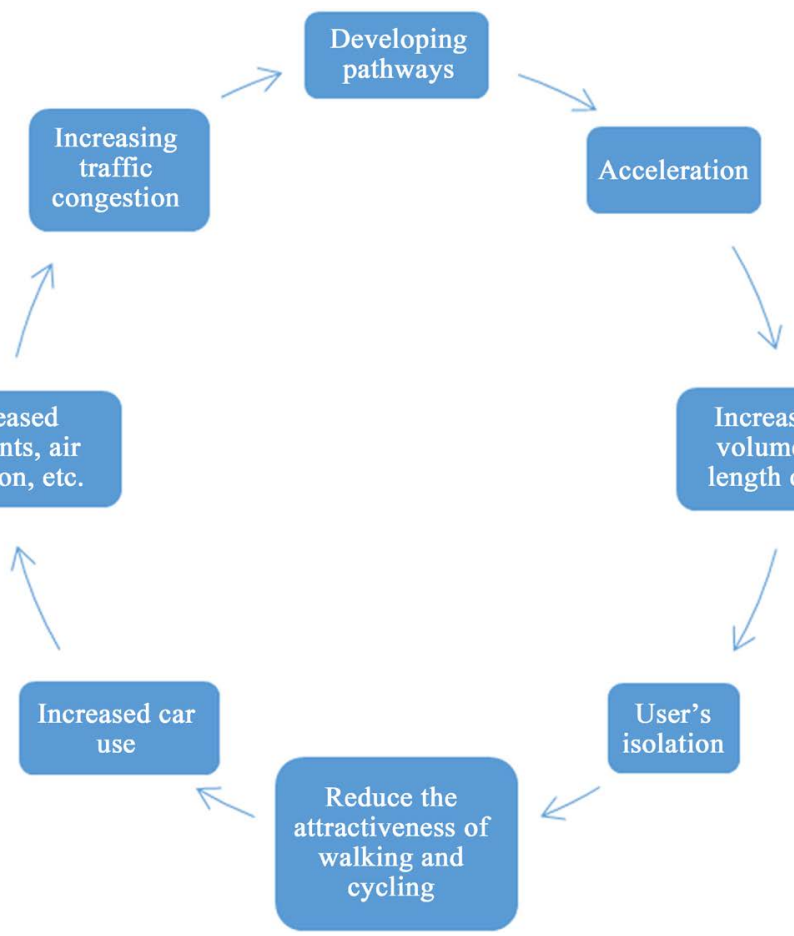
transport with personal vehicles or passenger carrier transport except taxis that this issue is considered as the main source of air pollution in the Kerman city. Today the safety caused by traffic is the main concern of this city. In 2009, 19,200 traffic accidents have been recorded in the Kerman city, and crowded urban paths such as Azadi Square and Jomhoori Blvd are the most accident prolific areas. The lack of adequate security caused by high seismicity accidents on the sidewalks nearby the main arteries, has reduced the utility of these trails. In Kerman city, public transport systems include buses and taxis. Already in Kerman city in 3 regions, about 152 thousand passengers are transported by bus every day, Also, about 5 thousand taxis move about 300 thousand people every day, But the willingness of residents to use personal cars is caused a slow transport in the main axes of the city center. Some experts say one reason for the high volume of traffic in Kerman is annual increase of 30 thousand units of vehicles traveling on the streets of this town [17].

\section{Theoretical Framework}

\subsection{Sustainable and Human-Oriented Transportation}

Nowadays what the world transport experts agree on it, is achieve to human-oriented and sustainable transport model so it can provide a safe, quiet urban landscape of the city with fast, safe and efficient for all citizens [18]. The CST, Centre for Sustainable Transportation, developed a definition of sustainable transportation system:

Allows the basic needs of individuals and societies to be met safely and in a manner consistent with human and ecosystem heal this affordable, operates efficiently, offers choice of various transportation modes, and supports a booming economy. Limits emissions and waste so that plants are able to absorb them, minimizes consumption of non-renewable resources, limits consumption of renewable resources to the sustainable level, reuses and recycles its components, and minimizes noise pollution and use of land [19].

The concept of sustainable transportation is vital to ensure environment clean, healthy and high quality. So it emphasizes on the human life and the environment, to meet current and future needs. Today, the transportation systems in major cities have shown a bad image because of have traffic congestion, accidents, lack of access to public transport and carbon emissions to the atmosphere of space contributes to environmental pollution and imbalance in terms of quality of life in general mobility. Along with the promising concept of sustainable transport services to consumers and at the same time ensure the safety of road users and also help towards the welfare and the environment [20]. Transportation facilities and activities have significant sustainability impacts, including those listed in Table 1.

Sustainable transport system can be defined also as a transportation demand but does not affect future transport demand [22]. And Sustainability is not about threat analysis; sustainability is about systems analysis. Specifically, it is about how environmental, economic and social systems interact to their mutual advantage at various space-based scales of operation [23].

Transportation planning that is able to promote the concept of sustainability, refers to a comprehensive and strategic planning that consider the long time and indirect effects of environmental, social and economic components and boost the sustainable planning that emphasize on development instead of growing as enhancing quality factor and consider the resource constraints and risks, including the reduction of fossil fuels and climate changes [24]. New strategies for urban transportation based on sustainable transport policy insist on qualitative and quantitative developing of public transport, increase ability to walk or increase the potential for using non-motorized systems such as walking and cycling, travel demand management, reduce the use of private cars and promotion of traffic [25]. In fact designing walk spaces in the twentieth century was a rejection to moderni-

Table 1. Transportation impacts on sustainability [21].

\begin{tabular}{ccc}
\hline Economic & Social & Environmental \\
Traffic congestion & Inequity of impacts & Air and water pollution \\
Mobility barriers & Mobility disadvantaged & Habitat loss \\
Accident damages & Human health impacts & Hydrologic impacts \\
Facility costs & Community interaction & Depletion of non-renewable resources \\
Consumer costs & Community livability & Aesthetics \\
\hline
\end{tabular}


zation of traffic and the development of consumer culture [26]. Approach of sustainable transportation follows principles such as human-oriented, the prioritize access, street as traffic space and substrate interview, the integration of people and traffic and traffic calming, developing public transport infrastructures and correcting the behavior patterns and escalating rules for reduce the effects of vehicles. Humanistic approach in urban transportation is a significant factor in reducing dependence on vehicle. Environmental factor can play a role in inhibiting the motor patterns and encourage people to walk and ride bicycles [27]. Achieving the goals of sustainable transport and increasing the share of non-motorized transport in urban travels, requires a combination of policies related to the use of new technologies, economic incentives and disincentives, along with a review of the principles and methods of urban planning. Walking and cycling are accommodating with environment and sustainable transportation and in order to replace them with the motor vehicles in short-distance trips they required to make infrastructures and components [6].

However, walk ability does not inevitably eradicate car dependency. People may live in walk able neighborhoods in which they can walk to the grocery store or their gym, but they may still need a car to get to work or other places [28].

\subsection{Non-Motorized Transport (NMT)}

Non-motorized transport (NMT), cover walking, cycling and other modes of transport (skates, wheelchairs, carts), in which the required force to move people and goods provided through the muscle force [29]. Non-motorized transport modes are often considered as essential element of sustainable transport system. This includes walking, cycling, rickshaws, animal-drawn carts and rollerblading or skating [30]. These physical activity related to transport (TPA ${ }^{1}$ ), currently are discussed as a sustainable solution to decrease the burden on public health and transportation [31].

NMT which includes walking and cycling is increasingly being favored as an attractive alternative to motorized commuter journeys by policymakers and environmentalists. Favorable NMT policies and increased NMT mode share can provide both personal and social benefits. The individual benefits are improved health and fitness, basic mobility, improved accessibility and cost effective travel. The social benefits are congestion reduction, roadway and parking infrastructure cost savings, energy conservation, reduced air and noise pollution and reduced accident risks to other road users [32]. These modes of transport can provide both recreation and transportation. For example, some people will choose to walk or bicycle rather than drive because they enjoy the activity [20].

Litman says that option of non-motorized mobility can create different advantages and disadvantages (Table 2) and includes direct benefits for consumers that arises from improving the conditions of walking and cycling, also creates various benefits for society caused by increased activity of walking and cycling, reduce car travel and from the mixing of land uses and high density developing patterns. Since low-income people physically and economically are dependent to walking and cycling, improve this state is helpful for desire to increase social justice [29]. Leon Crier believes that man should use his legs for a better aim than walking towards his car, Underground trains and planes and move less with vehicles [4].

In Iran, there haven't done any activities to strengthen these kinds of trips, except for the old cities, especially in

Table 2. Advantages and disadvantages of non-motorized transportation.

$\begin{array}{cl} & \text { Improve user comfort, access improvements especially for pedestrian, up grading the walking, increase local property } \\ \text { values, reduce traffic congestion, [6], high level of the sense of neighborhood and increase the sense of belonging, enhance } \\ \text { readability location, high level of awareness, increase environmental safety and security, reduce crime and violence, taking } \\ \text { into account the needs of persons with disabilities [33], enhance environmental quality and reduced forms of pollution, } \\ \text { energy conservation, increase biodiversity, conservation, encouraging mixed land uses, health promotion and public health } \\ \text { Petential } \\ \text { [34], reduction in sudden death, reduce obesity and overweight [35], Increase access to public transport, equal access to } \\ \text { goods , services and facilities, reduce energy consumption, strengthen environmental education and cultural traditions, } \\ \text { preserve the old and historic textures, improve leisure, shaping the structure of settlements, save money roads and parking } \\ \text { facilities, saving transport costs [3]. } \\ \text { Potential } \\ \text { Increasing accident risk, increasing travel time, increasing of development costs [6], Speed limits, restrictions on move- } \\ \text { ment distance, and limitations in mobility for people with disabilities [3]. }\end{array}$

\footnotetext{
${ }^{1}$ Transport-related physical activity.
} 
bazaar and there is not any facts and statics that specifies the size, role and status of this system. Unlike our country, most industrial countries have done extensive works in this area in order to reduce the issues of central part and priority access. In the United Kingdom more than 60 percent of trips under $1 / 5 \mathrm{~km}$ just take place on foot and it is said that in urban areas, about one third of all trips are done on foot [9].

\subsection{Walking and Urban Form}

Wherein the share of traffic that is carried out on foot be more, structured settlements will be stronger, more diverse and yet free from crisis, so the pedestrian should travel in all the settlements, as sure, with no problem and easy. Intrinsic feature of pedestrian, induced differentiation him from other types of traffic: flexibility and rapid self-regulation, the pedestrian is adapting him with natural conditions [36]. Statistics indicate that on average, 7 percent of urban trips are done entirely by walking and at least in 20 to 30 percent of trips, part of the route to be walked [37]. Healthy foot environment can be successful without a transportation system, but the transportation system cannot exist without pedestrians [38]. Walk ability is often associated with suitability factors such as street width, the number of lanes, safe speeds, crossing improvements, the presence of trees, and other pedestrian level of service and suitability factors [39]. Others cite the perception of safety, such as the fear of crime or heavy traffic [28].

\subsection{Walk Ability and Health}

Studies have found that neighborhoods classified as walk able (using walk ability benchmarking tools) have higher levels of incidental walking and a lower incidence of obesity [40]. One study reported that obesity is responsible for 2.6 million annual deaths worldwide. The American Obesity Association (2007) reports that 65\% of American adults are overweight and 30.5\% are considered obese; in addition, the rate of obesity is expected to double within the next 10 years (U.S. Center for Disease Control). Being overweight or obese increases the risk of developing high blood pressure, high cholesterol, heart disease, stroke, cancer, gallbladder and respiratory disease, joint and bone disease, and diabetes [41].

Studies suggest that obesity is mitigated by increased activity associated with a more walk able environment. Studies have shown that light-to-moderate activity is associated with a substantially reduced risk of developing disease. Many urban planning scholars agree that the built environment influences physical activity levels [28]. Furthermore, environments that are more walk able are correlated with a decreased risk of obesity and related illnesses [42].

\subsection{Walk Ability, Economic Value and Demand}

A growing body of work shows that walk able neighborhoods have intrinsic economic value by encouraging economic transactions and social exchanges and bolstering real estate property values in addition to promoting health benefits [28]. Research by Matthews and Turnbull (2007) showed that a more grid-like street pattern increased property values in more pedestrian-oriented neighborhoods and decreased property values in automobile-oriented neighborhoods. Other work finds that each incremental increase in walk ability, using walk score as a metric, can be associated an increase in property values of up to $9 \%$ [43].

Improved walk ability can entice consumers to purchase more local goods and promote greater economic resilience. The attributes associated with walk ability may also have the capacity to improve safety and decrease crime [44], which has an indirect effect on real estate values. There is also literature suggesting that walk ability bolsters real estate values. A recent study showed that a spike in consumer demand for walk able neighborhoods spans socio-economic statuses [45]. This finding is somewhat at odds with the conventional wisdom that upper-income families (especially Caucasians) prefer large, single-family, single-use suburban homes and racial homogeneity [28].

The purpose is not to prohibit the use of car, because not only it is not physically possible, but also there no economical and rational justification and on the other hand, it is in conflict with the common human values such as freedom and individual choice. Instead, the goal is living in a city, does not require people to acquire and frequent use of the vehicle [46]. Therefore, the implementation-oriented of urban projects should be considered in urban plans and adequate funding should be assigned to implement them, because the budget is ensure for the implementation of a strategy. 


\section{Analysis}

According to the considered thoughts, municipalities in the country as the main administrant of urban projects and programs and as well urban management in cities, transport requires the definition of plans and projects related to this topic in order to implement programs related to human-oriented and sustainable transport. Moreover, each project requires adequate funding to be operated. In following papers, the budget changes during the past six years in the Kerman city have been reviewed.

As it is clear from Table 3, at the beginning of the six-year period a significant share of the total budget for urban development (56.19\%) are dedicated to improving transportation programs and urban traffic, but this value has declined during the later years of study, so that in the last year of study it became $37.94 \%$ of the total budget for urban development. This descent shows the reduction of planner's attention and descent of transport plan dock and urban transit improvement in the total budget allocated for urban development. However, as it comes out from the numbers this decline is not quite regularly, the process was descending from 2009 the beginning of study period until 2012, But in 2013, it can be seen about 7 percent jump in transport budget share of the total budget, after that there is a decreasing trend in the end of the period.

As well according to Figure 2 the amount of funds allocated to the various plans related to urban transport and transit doesn't have a regular process, so that it has decreased in the years 2010 and 2012 than in previous years. And in other years it has an increasing trend, especially it has increased significantly in the last two years, the years 2013 and 2014.

Also a percentage of urban development costs spent on land and property acquisition needed to create the transport infrastructures. According to financial planning of Kerman city hall, the budget for planning and urban development will be divided between the land and estate acquisition and various study projects. At the beginning of the review period in 2009 the project of property and land acquisition amounted to199.04 million Riyals, allocated to itself about $5 \%$ of the total budget of urban development (Figure 3). This budget has been increased during the study period, which in 2014 it is amounted to 1600 million Riyals, which became about $12 \%$ of the development budget. This increased funding for land ownership and urban property by the municipality indicates irregular widening of passages and the creation of urban spaces for pathways and traffic bridge.

In this six years property and land acquisition has owned more budget than the study projects and a major share of the budget of urban development planning is cost in this part, while with further studies and thus allo-

Table 3. The amount of budget for urban development and transportation plan and reform of urban traffic in Kerman city in 2009-2014 (Currency Riyal).

\begin{tabular}{|c|c|c|c|c|c|c|}
\hline Title & 2009 & 2010 & 2011 & 2012 & 2013 & 2014 \\
\hline $\begin{array}{l}\text { Total of budget for } \\
\text { urban development }\end{array}$ & $4,406,350,000$ & $4,511,440,000$ & $5,998,810,000$ & $7,775,100,000$ & $8,666,930,000$ & $13,415,200,000$ \\
\hline $\begin{array}{l}\text { Total of transportation plan } \\
\text { and reform of urban traffic }\end{array}$ & $2,476,160,000$ & $2,168,340,000$ & $2,803,380,000$ & $2,780,170,000$ & $3,668,500,000$ & $5,089,900,000$ \\
\hline $\begin{array}{l}\text { Percentage of transportation } \\
\text { plan and reform of urban traffic }\end{array}$ & 56.19 & 48.06 & 46.74 & 35.76 & 42.33 & 37.94 \\
\hline
\end{tabular}

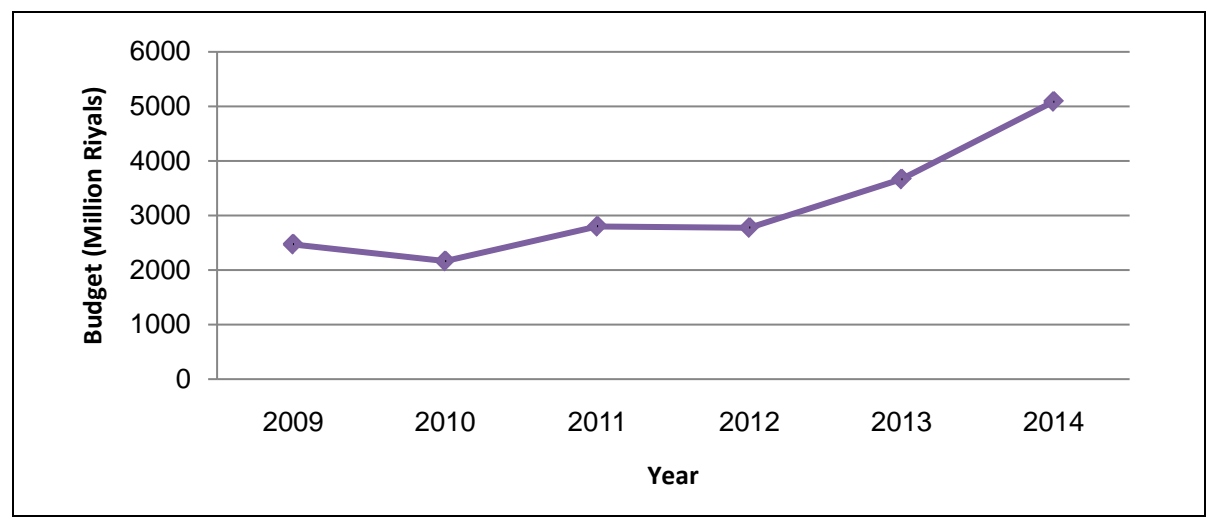

Figure 2. The budget of transportation program and reform of urban traffic from 2009 to 2014. 


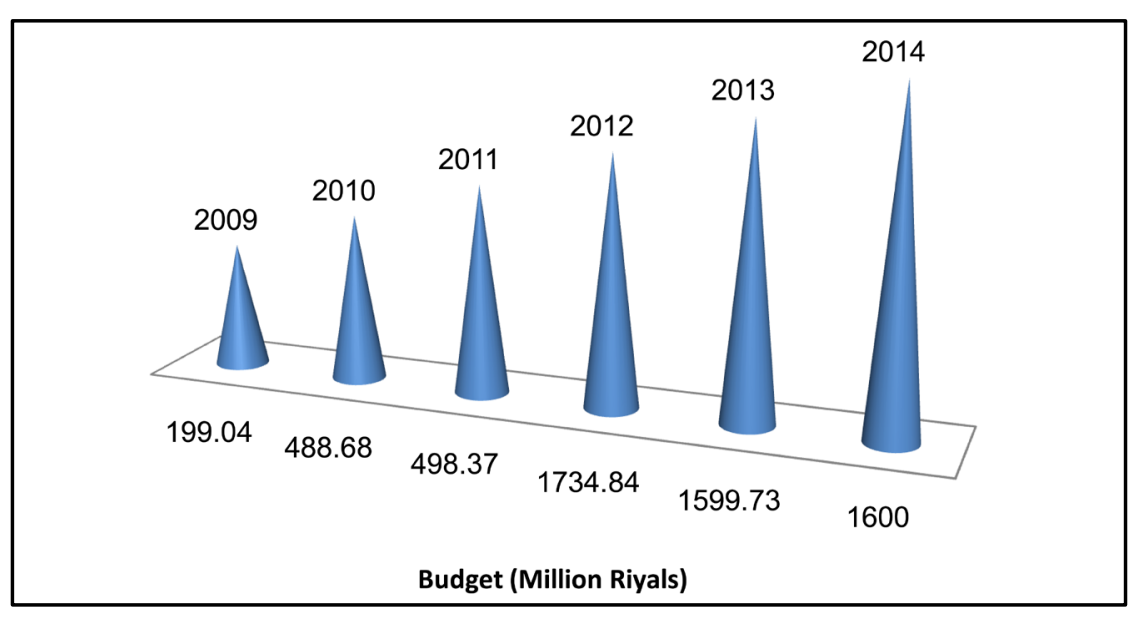

Figure 3. The budget of land and property acquisition from 2009 to 2014.

cate more funding for the study plans can present plans that are compatible with human-orientated and sustainable transportation.

The budget allocated to transportation plan and reform of urban traffic, is distributed in nine projects related to the program. Each of the projects allocates a part of the total budget according to their importance. The titles of these nine plans are as follows:

- The plans of infrastructure, curb and asphalt pavements;

- The plan of Implementation of the pavement;

- The plan of construction and completion of the bridge over the river and under pass bridge of urban streets;

- The plan of completion and construction of public parking;

- The improvement plan of traffic in the old texture of city;

- The plan to help the bus;

- The plan of improving traffic;

- Master plan of organizing urban transport;

- The plan of construction of the urban belt.

Table 4 shows the change in the budget for each of the nine parts in years of the study. Figure 4 shows the percentage the budget of various transportation plans and reform of urban traffic during 2009-2014.

As it is clear in each of the years of study, the plans of infrastructure, curb and asphalt pavements allocated to themselves greatest share of the total budget.

The lowest level of appropriations is different in the years of the investigation, in 2009, the beginning of the review period, the plan of completion and construction of public parking and the improvement plan of traffic in the old texture of town allocated a very little amount of funds nearly zero percent to themselves. While via the allocation of more funds to improve transport in the old urban texture can move towards sustainable development, because these textures are formed on the basis of sustainable development.

In 2010 this share allocated to the improvement plan of traffic in the old texture of city. In 2011, again improvement plan of traffic in the old texture of city and in addition to that The plan of construction of the urban belt had a very small amount of budget, in 2012 the plan of construction of the urban belt, in 2013 completion and the plan of construction of public parking , master plan of organizing urban transport and the plan of construction of the urban belt and finally at the end of the review period, in 2014 the plan of construction of the urban belt have the lowest amount of budget.

The plans of Infrastructure, curb and asphalt pavements at the beginning of the review period in 2009 allocate to itself the maximum amount of funding, and over the next years it has a decreasing trend, especially in 2011 it has decreased considerably compared to the previous year. Totally the plans of infrastructure, curb and asphalt pavements have passed decreasing trend during the study years.

During the six-year period the plan of implementation of the pavement has very limited changes and almost in all of these six years the same rate and very little funding has been allocated to it. However, generally it had an increasing trend and the amount of budget has increased from 70,120,000 Riyals in the first year of the review to 
200,000,000 Riyals in the end year. Despite this trend of increasing, the amount of funds allocated to it indicates that, While for expanding of the network of roadways and their equip massive spending are allocated, at the same time, public transport systems and cycling and walking networks as sustainable transport options, less attention were paid.

The plan of construction and completion of the bridge over the river and underpass bridge of urban totally has an ascending and descending process. Such that from 2009 to 2011, it has increased and has dramatically increased from 93,490,000 Riyals to 987,520,000 Riyals. After that in 2012 the amount of budget has decreased 226.06 million Riyals. In the following year we can see a big jump in budget, 848.65 million Riyals and at the end of the year it's lightly decreases compared to previous year and the rate reaches to1500 million Riyals.

The budget of the plan of completion and construction of public parking has an increasing and decreasing process, In 2009 the beginning of the study period, allocated to it a tiny proportion of budget, In two next years, can be observed approximately14-fold increase in the budget. In two next years, the direction of process has changed and sailed to reduce until in 2013 it became approximately zero, but in the last year of review in 2014 has been found a 10 percent increase. Due to the severe shortage of public parking in Kerman city especially in the central parts of the city that has more commercial uses, it is expected that additional funding by the municipality and relevant organs to it be assigned.

The budget of the improvement plan of traffic in the old texture of city totally has an increasing process except in 2013 that it had a slight decrease compared to the previous year. But in general, this plan allocated to itself a small percentage among the nine plans of urban traffic. Despite the wide range of Kerman is formed by

Table 4. The change in the budget of various transportation plans and reform of urban traffic during 2009-2014 (Currency Riyal).

\begin{tabular}{|c|c|c|c|c|c|c|}
\hline Title & 2009 & 2010 & 2011 & 2012 & 2013 & 2014 \\
\hline $\begin{array}{l}\text { The plans of infrastructure, } \\
\text { curb and asphalt pavements }\end{array}$ & $1,840,890,000$ & $1,532,510,000$ & $1,157,630,000$ & $1,225,930,000$ & $1,438,100,000$ & $1,736,000,000$ \\
\hline Percentage of transportation plan & $74 \%$ & $71 \%$ & $41 \%$ & $44 \%$ & $39 \%$ & $34 \%$ \\
\hline $\begin{array}{l}\text { The plan of Implementation } \\
\text { of the pavement }\end{array}$ & $70,120,000$ & $82,680,000$ & $73,380,000$ & $136,700,000$ & $101,620,000$ & $200,000,000$ \\
\hline Percentage of transportation plan & $3 \%$ & $4 \%$ & $3 \%$ & $5 \%$ & $3 \%$ & $4 \%$ \\
\hline $\begin{array}{l}\text { The plan of construction and } \\
\text { completion of the bridge over } \\
\text { the river and under pass bridge } \\
\text { of urban streets }\end{array}$ & $93,490,000$ & $146,670,000$ & $987,520,000$ & $761,460,000$ & $1,610,110,000$ & $150,000,0000$ \\
\hline Percentage of transportation plan & $4 \%$ & $7 \%$ & $35 \%$ & $27 \%$ & $44 \%$ & $29 \%$ \\
\hline $\begin{array}{l}\text { The plan of completion and } \\
\text { construction of public parking }\end{array}$ & $8,440,000$ & $61,020,000$ & $145,180,000$ & $93,830,000$ & 0 & $500,000,000$ \\
\hline Percentage of transportation plan & $0 \%$ & $3 \%$ & $5 \%$ & $5 \%$ & $0 \%$ & $10 \%$ \\
\hline $\begin{array}{l}\text { The improvement plan of traffic in } \\
\text { the old texture of city }\end{array}$ & $7,230,000$ & $10,640,000$ & $13,210,000$ & $33,220,000$ & $26,450,000$ & $117,500,000$ \\
\hline Percentage of transportation plan & $0 \%$ & $0 \%$ & $0 \%$ & $1 \%$ & $1 \%$ & $2 \%$ \\
\hline The plan to help the bus & $211,320,000$ & 153790000 & $203,570,000$ & $322,880,000$ & $371,320,000$ & $350,000,000$ \\
\hline Percentage of transportation plan & $9 \%$ & $7 \%$ & $7 \%$ & $12 \%$ & $10 \%$ & $7 \%$ \\
\hline The plan of improving traffic & $92,880,000$ & $111,590,000$ & $128,020,000$ & $100,040,000$ & 12,090 & $186,400,000$ \\
\hline Percentage of transportation plan & $4 \%$ & $5 \%$ & $5 \%$ & $4 \%$ & $3 \%$ & $4 \%$ \\
\hline $\begin{array}{l}\text { Master plan of organizing } \\
\text { urban transport }\end{array}$ & $27,440,000$ & $54,460,000$ & $94,870,000$ & $106,110,000$ & 0 & $500,000,000$ \\
\hline Percentage of transportation plan & $1 \%$ & $3 \%$ & $3 \%$ & $4 \%$ & $0 \%$ & $10 \%$ \\
\hline $\begin{array}{l}\text { The plan of construction } \\
\text { of the urban belt }\end{array}$ & $124,350,000$ & $14,980,000$ & 0 & 0 & 0 & 0 \\
\hline Percentage of transportation plan & $5 \%$ & $1 \%$ & $0 \%$ & $0 \%$ & $0 \%$ & $0 \%$ \\
\hline $\begin{array}{l}\text { Total of transportation plan } \\
\text { and reform of urban traffic }\end{array}$ & $2,476,160,000$ & $2,168,340,000$ & $2,803,380,000$ & $2,780,170,000$ & 3668500000 & 5089900000 \\
\hline
\end{tabular}




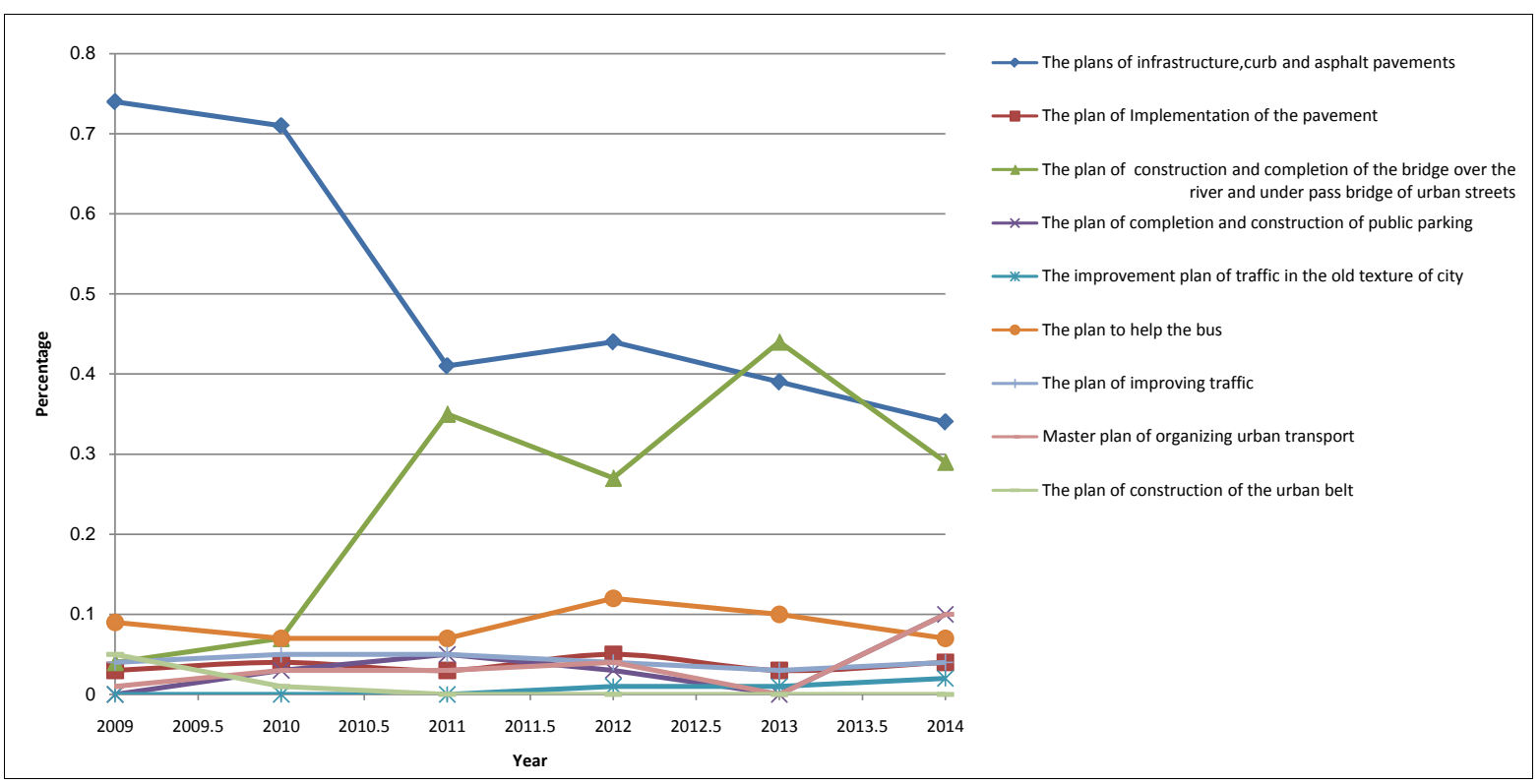

Figure 4. The percentage the budget of various transportation plans and reform of urban traffic during 2009-2014.

old and worn texture and consequently the traffic in these areas should be arranged and therefore it requires additional funding. Very small amount of funding allocated to it, shows lack of attention to the old and worn texture of city and organizing and improving it, however, the old textures of Kerman were formed on the principles of sustainable architecture and urbanism as a result, traffic in these places is human-oriented.

The budget of the plan to help the bus had decreased just at the beginning and the end of the study period and in other years the trend has been increasing. But generally at the end of the study period, this share have fallen in terms of percentage share of the total budget funds of urban transport and transit compared to the first year, While public transport system should be in order to achieve sustainable transport spread.

The budget of the plan to improve traffic has increased over the six-year period and from 92,880,000 Riyals at the beginning of the review period achieved to 186,400,000 Riyals at the end of the period. However, its contribution of total funding share is small.

The budget of the plan of construction of the urban belt, is zero in all these years except for first and second year of study, the reason is that the plan of city within beltway is implemented.

Figure 5 shows the total sum of each the nine projects over a six-year study. As it is clear during the six-year period and totally, the plans of Infrastructure, curb and asphalt pavements, with 47 percent of the total 100\% has the largest share, After that there is The plan of construction and completion of the bridge over the river and underpass bridge of urban streets ,Then with a large difference there is the plan of help to bus And then there are master plan of organizing urban transport, traffic improvements, Construction and completion of the public parking and Implementation of the pavement with low percent, 4 percent. And at the end there are the plan of construction of the urban belt and the improvement plan of traffic in the old texture of city.

Among all of under taken plans there is just the plan of implementation pavement that takes steps toward non-motorized transportation. During the six-year period, the plan of implementation pavement had very limited changes and almost in all of the study years has been allocated to it on the same level and very little funding (Figure 6). But none the less the general trend has been increased and from the budget 70,120,000 Riyals in the first year of study achieved to 200,000,000 Riyals in the final year of period. Since this mode of transport is very cheap, it needs much less financial resources than other transport projects to create the infrastructures. While if even will be reduced one percent of other programs, can be created non-motorized transport infrastructure in many fields. Pedestrian-oriented of urban projects should be a priority for urban projects and adequate funding to implement them properly; since the budget guarantee the implementation of a strategy.

Since Kerman city is a historic city with wide spread old texture, it is expected that further funds be allocated for projects that will improve traffic in the old texture and move it to more cycling and walking, unfortunately, the budget process does not show this. 


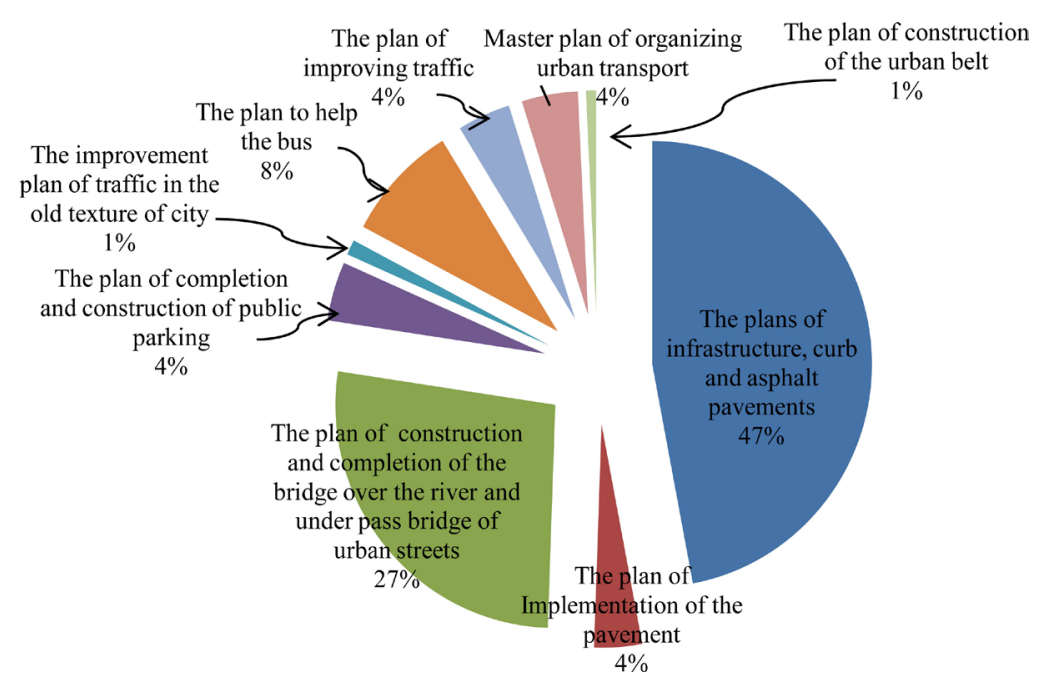

Figure 5. The percentage of total sum of each the nine projects (2009-2014).

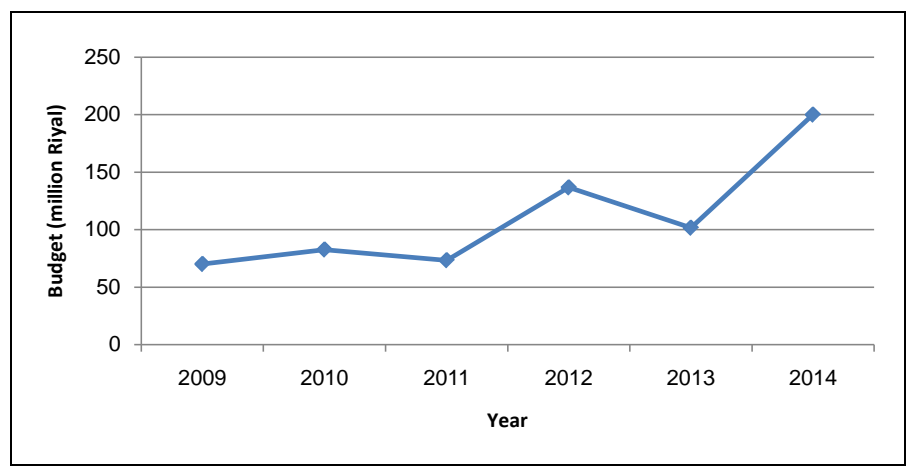

Figure 6. The budget of Implementation of the pavement plan (2009-2014).

\section{Conclusions}

Nowadays, transportation system is entirely for the benefit of drivers and thus is beneficial to vehicle traffic from predict stage to conclusions stage. However, today, to deal with environmental risks, increase the level of social interaction, save costs of transport and contribute to the health, we need to seek alternatives to car use.

In this case, managers and planners in the design and planning of city hall projects can provide the base of non-motorized models in network traffic by leading the city hall projects with low costs and make such problems less in cities. Bicycle transportation and pedestrian system are including these systems. This system has many advantages such as improving health, reducing household spending, reducing the cost of transportation and construction of infrastructure, reducing air pollution and dependence on non-renewable resources that will be usable for a wide range of social classes and it has significant economic benefits for the city as well.

Unfortunately, in the development plans of Kerman city, it has not been paying attention to this transport system and this is specified via very small share of the budget allocated to the sector's development plans and programs municipality.

Another important point is that the extremely low budget allocated to improve traffic in the old texture of city, despite the wide range of Kerman city consists of old texture that it has very bad transportation condition. Since the old texture of Kerman is formed on the principles of sustainable living, including pedestrians, so it is better that the authorities pay more attention to this section in order to take a major step forward to human-oriented transport. If only allocated apart of the overall funding for roads, highways and city streets to the development of public transport and non-motorized transportation options, the impact would be very high. Generally, we should change the heading city hall planning, and implementation-oriented and biking receive more shares from the budget. City hall projects must be in the form of urban development plans, programs and strategies that walk- 
ing-oriented system and biking and ultimately human-oriented transportation become top of view.

Projects of development plans in Kerman city can be in the form of the following strategies to promote human-orientated and the transportation system, which is defined as following:

- Developed plans of study for effective factors on the increased use of non-motorized transportation;

- Revising the terms of zoning and development plans based on the walking and sustainable access;

- Information and promotional plans to reduce the use of private cars;

- Providing of support facility in public and private places, such as the location of the stop and park of the bike, pedestrians and cyclists specific inputs to provide comfort;

- Using the potential in the historic texture of the city to assign it to specific routes on foot;

- Break down of trails, pedestrian and bike rides and create safety for pedestrians and cyclists;

- Continuity of sidewalk network and transition and pause spaces in the human scale and optimal pedestrian.

\section{References}

[1] United Nations Human Settlements Programme (2013) State of the World's Cities 2012/2013: Prosperity of Cities.

[2] Schwanenm, T. (2002) Urban Form and Commuting Behaviour: A Cross-European Perspective. Journal of Economic and Social Geography, 93, 336-343.

[3] Khaksari, A. and Kheradmand, M. (2013) Comparison of Vehicle-Oriented and Human-Oriented Transportation. Journal of RAHVAR, 22, 129-150.

[4] Bahrayni, H. Blocky, B. and Taqabon, S. (2009) Theoretical Analysis of Contemporary Urban Design. Tehran University, Tehran.

[5] Tibaldz, F. (2001) Human-Oriented Cities: Improving the Environment in Towns and Cities. Tehran University Publishing and Printing Institute, Tehran.

[6] Soltani, A. (2014) Analysis of the Role of Sustainable Transport Infrastructure in City Hallities Projects. Journal of Research and Urban Planning, 16, 1-18.

[7] Piatkowski, D., Krizek, K. and Handy, S. (2015) Accounting for the Short Term Substitution Effects of Walking and Cycling in Sustainable Transportation. Journal of Travel Behaviour and Society, 2, 32-41. http://dx.doi.org/10.1016/j.tbs.2014.07.004

[8] Schiller, P., Bruun, E. and Kenworthy, J. (2010) An Introduction to Sustainable Transportation (Policy, Planning and Implementation). Earthscan Press, London.

[9] Ahadi, M.R. (2011) Traffic and Safety Engineering. Naja Police University Press, Tehran.

[10] Jahanshahi, K. (2005) Transport System in Urban Centers and the Question for Down Town of Tehran. Journal of Urban Development, 12, 34-49.

[11] Hansen, M. and Huang, Y. (1997) Road Supply and Traffic in California Urban Area. Journal of Transportation Research, Part A, 31, 14-22. http://dx.doi.org/10.1016/s0965-8564(96)00019-5

[12] Gurr, R. (2005) Ford's Magic Skyway and the Peoplemover. Extinct Attractions Club, United States.

[13] CDPH (2011) Health Co-Benefits and Transportation-Related Reductions in Greenhouse Gas Emissions in the Bay Area: Technical Report. California Department of Public Health, Producer. http://www.cdph.ca.gov/programs/CCDPHP/Documents/ITHIM-Technical-Report11-21-11.pdf

[14] Grabow, M., Spak, S., Holloway, T., Stone, B., Mednick, A. and Patz, J. (2011) Air Quality and Exercise-Related Health Benefits from Reduced Car Travel in the Midwestern United States. Environmental Health Perspectives, 120, 68-76. http://dx.doi.org/10.1289/ehp.1103440

[15] Research Center of Mashhad City Council (2008) European Plan to Reduce Traffic in the Three City, Dating from the Urban Management (Global Experience). No. 107.

[16] Department of Statistics and Planning of Kerman City (2014) Kerman City Hall Statistical Year Book, Years 20092014.

[17] The Deputy of Kerman City hall Transportation Planning (2014) Report of the Third Stage of the Kerman Transport Scheme.

[18] Hallo, J. and Manning, R. (2009) Transportation and Recreation: A Case Study of Visitors Driving for Pleasure at Acadia National Park. Journal of Transport Geography, 17, 491-499. http://dx.doi.org/10.1016/j.jtrangeo.2008.10.001

[19] Haghshenas, H., Vaziri, M. and Gholamialam, A. (2015) Evaluation of Sustainable Policy in Urban Transportation Using System Dynamics and World Cities Data: A Case Study in Isfahan. Journal of Cities, 45, 104-115.

[20] Mat Yazid, M.R., Ismail, R. and Atiq, R. (2011) The Use of Non-Motorized for Sustainable Transportation in Malaysia. 
Proceedings of the 2nd International Building Control Conference, Penang, 11-12 July 2011, 125-134.

[21] Litman, T. and Burwell, M. (2006) Issues in Sustainable Transportation International. Journal of Global Environment Issues, 6, 331-347. http://dx.doi.org/10.1504/IJGENVI.2006.010889

[22] Black, W.R. (1997) North American Transportation: Perspectives on Research Needs and Sustainable Transportation. Journal of Transport Geography, 5, 12-19. http://dx.doi.org/10.1016/S0966-6923(96)00042-7

[23] World Commission on Environment and Development (1987) Our Common Future Brundtland Report. Oxford University Press, Oxford.

[24] Litman, T. (2011) Planning Principles and Practices. Victoria Transport Policy Institute, Victoria.

[25] Tajdar, V. and Akbari, M. (2009) International Approach to Urban Public Transport. Proceedings of the Second Transport and Traffic Conference, Tehran, 4 September 2009, 37-49.

[26] Zacharias, J. (2001) Pedestrian Behavior and Perception in Urban Walking Environmental. Journal of Planning Literature, 16, 13-18. http://dx.doi.org/10.1177/08854120122093249

[27] Moeini, M. (2011) Pedestrian-Oriented Cities. Azarakhsh Press, Tehran.

[28] Gilderbloom, J., Riggs, W. and Meares, W. (2015) Does Walkability Matter? An Examination of Walkability’s Impact on Housing Values, Foreclosures and Crime. Journal of Cities, 42, 13-24. http://dx.doi.org/10.1016/j.cities.2014.08.001

[29] Litman, T. (2012) Evaluating Non-Motorized Transportation Benefits and Costs. Victoria Transport Policy Institute, Victoria.

[30] Raha, U. and Taweesin, K. (2013) Encouraging the Use of Non-Motorized in Bangkok. Procedia Environmental Sciences, 17, 444-451. http://dx.doi.org/10.1016/j.proenv.2013.02.058

[31] Badland, H.M., Schofield, G.M. and Garrett, N. (2008) Travel Behavior and Objectively Measured Urban Design Variables: Associations for Adults Traveling to Work. Journal of Health \& Place, 14, 85-95. http://dx.doi.org/10.1016/j.healthplace.2007.05.002

[32] Lawson, A.R., Mcmorrow, K. and Ghosh, B. (2013) Analysis of the Non-Motorized Commuter Journeys in Major Irish Cities. Journal of Transport Policy, 27, 179-188. http://dx.doi.org/10.1016/j.tranpol.2013.01.007

[33] TDOT (2005) Bicycle and Pedestrian Element. Tennessee Long-Range Transportation Plan.

[34] Kashanijou, K. (2011) Evaluation Integration between Public Transportation and Pedestrain-Oriented Urban Space un Two Main Metro Station of Iran. Scientific Research and Essays, 13, 269-279.

[35] Bauman, A.E. and Bull, F.C. (2007) Environmental Correlates of Physical Activity and Walking in Adults and Children: A Review of Reviews. Review under Taken for National Institute of Health and Clinical Excellence.

[36] Kent Lakher, H. (2002) Pedestrian and Bicycle Traffic Planning Principles. Tehran University Publishing and Printing Institute, Tehran.

[37] Litman, T. (2003) Evaluating Rial Transit Criticism. Victoria Transport Policy Institute, Victoria.

[38] Calthorpe, P. (1993) The Next American Metropolis: Ecology, Community, and the American Dream. Princeton Architectural Press, New York.

[39] Dowling, R.G., Reinke, D.B., Flannery, A., Ryus, P., Vandehey, M., Petritsch, T.A. and Landis, B.W. (2008) NCHRP Report 616: Multimodal Level of Service Analysis for Urban Streets. Transportation Research Board of the National Academies, Washington DC.

[40] Frank, L., Kerr, J., Chapman, J. and Sallis, J. (2007) Urban Form Relationships with Walk Trip Frequency and Distance among Youth. American Journal of Health Promotion, 21, 1-8. http://dx.doi.org/10.4278/0890-1171-21.4s.305

[41] Foster, S. and Giles-Corti, B. (2008) The Built Environment, Neighborhood Crime and Constrained Physical Activity: An Exploration of Inconsistent Findings. Preventive Medicine, 47, 241-251. http://dx.doi.org/10.1016/j.ypmed.2008.03.017

[42] Frank, L.D., Schmid, T.L., Sallis, J.F., Chapman, J. and Saelens, B.E. (2005) Linking Objectively Measured Physical Activity with Objectively Measured Urban Form: Findings from SMARTRAQ. American Journal of Preventive Medicine, 28, 117-1325. http://dx.doi.org/10.1016/j.amepre.2004.11.001

[43] Pivo, G. and Fisher, J.D. (2011) The Walkability Premium in Commercial Real Estate Investments. Real Estate Economics, 39, 185-219. http://dx.doi.org/10.1111/j.1540-6229.2010.00296.x

[44] Troy, A. and Grove, J.M. (2008) Property Values, Parks, and Crime: A Hedonic Analysis in Baltimore, MD. Landscape and Urban Planning, 87, 233-245. http://dx.doi.org/10.1016/j.landurbplan.2008.06.005

[45] Handy, S., Sallis, J.F., Weber, D., Maibach, E. and Hollander, M. (2008) Is Support for Traditionally Designed Communities Growing? Evidence from Two National Surveys. Journal of the American Planning Association, 74, $209-221$.

[46] Soltani, A. (2011) Discussions on Urban Transport with a Focus on Sustainability Approach. Shiraz University Publication Center, Shiraz. 